\title{
The role of polyunsaturated fatty acids in restoring the aging neuronal membrane
}

\author{
Shlomo Yehuda ${ }^{\mathrm{a}, *}$, Sharon Rabinovitz ${ }^{\mathrm{a}}$, Ralph L. Carasso ${ }^{\mathrm{b}}$, David I. Mostofsky ${ }^{\mathrm{c}}$ \\ ${ }^{a}$ Psychopharmacology Laboratory, Department of Psychology, Bar Ilan University, Ramat Gan 52900, Israel \\ ${ }^{\mathrm{b}}$ Department of Neurology, Hillel Yaffe Hospital, Hedera, Israel \\ ${ }^{\mathrm{c}}$ Department of Psychology, Boston University, Boston, MA, USA
}

Received 29 August 2001; received in revised form 30 January 2002; accepted 11 April 2002

\begin{abstract}
In addition to a gradual loss of neurons in various brain regions, major biochemical changes in the brain affect the neuronal membrane that is the "site of action" for many essential functions including long-term potentiation (LTP), learning and memory, sleep, pain threshold, and thermoregulation. Normal physiological functioning includes the transmission of axonal information, regulation of membrane-bound enzymes, control of ionic channels and various receptors. All are highly dependent on membrane fluidity, where rigidity is increased during aging. The significantly higher level of cholesterol in aging neuronal membrane, the slow rate of cholesterol turnover, and the decreased level of total polyunsaturated fatty acids (PUFA) may result from poor passage rate via the blood-brain barrier, or from a decreased rate of incorporation into the membrane, or a decrease in the activities of delta- 6 and delta- 9 desaturase enzymes. The added oxidative stress, which leads to an increase of free radicals leading to a decrease in membrane fluidity, may respond to a restricted diet, and thereby overcome the damaging effects of the free radicals. A central focus of this review is that a specific ratio of n-3/n-6 PUFA can restore many of these age-related effects.
\end{abstract}

(C) 2002 Elsevier Science Inc. All rights reserved.

Keywords: Essential fatty acids; PUFA; Neuronal membrane; Aging

\section{Introduction}

Brain aging is a complex process involving many factors. Some are independent and others are inter-related. The aging brain is associated with many biochemical, physiological and behavioral deficiencies including, but not limited to, reduction of long-term potentiation (LTP), learning and memory loss, sleep disturbance, pain threshold alteration, and disturbed thermoregulation.

To better understand the aging process, the structural approach has been proposed, in which major structural changes occurring during this period are studied, e.g. the gradual loss of neurons in various brain regions. However, the course of the progression of these changes has not yet been established. While we know that it is a long and slow process, we do not know the appropriate statistic model to best predict the rate or form of the decline in either structure or function. The ability of the brain to create new synapses (synaptic genesis) is diminished during this period for rea-

\footnotetext{
${ }^{*}$ Corresponding author. Tel.: +972-3-531-8583; fax: +972-3-535-3327.
}

E-mail address: yehudas@mail.biu.ac.il (S. Yehuda). sons that are not understood. Concurrently, there are major biochemical changes in the brain that affect the neuronal membrane, that is the "site of action" for many essential functions. Such functions include the conduction of neuronal information along the axon, regulation of membrane bound enzymes, control of the ionic channels structure and activity, and maintenance of various types of receptors. During aging, the level of cholesterol in the neuronal membranes as well as the level of the toxic metabolite of cholesterol (24-OH-cholesterol) is greatly increased, and the corresponding rigidity of the neuronal membrane is significantly increased ([3]; see also Section 14 of this paper). The normal physiological functioning of the neuronal membrane is highly dependent on its structure, and while many factors can influence the membrane fluidity index, one of the major factors is the lipid composition of the membrane, where cholesterol reduces the membrane fluidity, and polyunsaturated fatty acids (PUFA) increase it. The brain can obtain long chain PUFA (LC-PUFA) directly from the diet, or it can use supplemented essential fatty acids (linoleic and alpha-linolenic) and convert them to longer chain fatty acids. 
This review will attempt to provide a better appreciation of the factors responsible for neuronal membrane rigidity, and thereby to suggest interventions that may be introduced to offset the unwanted outcomes. For example, given that the level of total PUFA is decreased in the aged, it may be attributed to (a) poor passage rate via the blood-brain barrier, or (b) decreased rate of incorporation into the membrane, or (c) a decrease in the activities of delta- 6 and delta- 9 desaturase enzymes. Each of these possibilities deserves examination.

In addition to PUFA, oxidative stress, which increases the level of free radicals [23], and which in turn induces a decrease in membrane fluidity [58], is yet another factor relevant for normal membrane composition. The incorporation of a restricted diet may overcome the damaging effects of the free radicals, and may offer a useful clinical intervention. Finally, previous studies have shown that dietary supplementation by a particular ratio of a mixture of n-3/n-6 PUFA exerts many beneficial effects, such as a reduced cholesterol level and an increased level of PUFA in the neuronal membrane [129]. It is our thesis in this report that this specific ratio of n-3/n-6 PUFA can restore many of the undesirable above-mentioned age-related effects. To support this hypothesis, we present a summary of relevant studies that have been confirmed experimentally and address this issue.

\section{Essential fatty acids}

The popular press routinely reports medical advisories urging the public to dramatically reduce the amount of fat they consume, in order to combat risks associated with cardiovascular disorders, diabetes, and other chronic disorders. Paradoxically, deficiencies in fat intake are likely to contribute to health hazards, including increased risk of infection, dysregulation of chronobiological activity, and impaired cognitive and sensory functions (especially in infants) [128]. Recently, Joseph et al. [60] reviewed the two conflicting roles of cholesterol, e.g. the "good" role of cholesterol and the "bad" role. A consensus from recent research suggests that it is not so much the amount of fat we eat, as the balance of the different types of fats, that is significant. The type of dietary fat affects how well the cell can perform its vital functions and its ability to resist disease.

Both linoleic and alpha-linolenic acids, the two PUFAs, are necessary for good health. They are called "essential fatty acids" (EFA) because the body cannot manufacture them or synthesize them. They must be provided by nutritional intake. Essential fatty acids are involved in energy production, the transfer of oxygen from the air to the bloodstream, the manufacture of hemoglobin, and are essential for normal nerve impulse transmission and brain function. They are also involved in growth, cell division and nerve function and are found in high concentrations in the brain, EFAs have beneficial effects when available in moderation.
Excesses of the otherwise beneficial fatty acids may, however, exert harmful effects, with high intakes of saturated and hydrogenated fats being linked to an increase in a number of health risks, including degenerative diseases, cardiovascular disease, cancer and diabetes.

\section{PUFA: polyunsaturated fatty acids}

Linoleic acid is a member of the family of omega- $6(n-6)$ fatty acids, while alpha-linolenic acid is an omega-3 (n-3) fatty acid. These terms refer to characteristics in the chemical structure of the fatty acids. Other omega- 6 fatty acids, such as gamma-linolenic acid (GLA), dihomo-gamma-linolenic acid (DHGLA) and arachidonic acid (AA), can be manufactured in the body using linoleic acid as a starting point. Similarly, other omega-3 fatty acids that are manufactured in the body, using alpha linolenic acid as a starting point, include eicosapentaenoic acid (EPA) and docosahexaenoic acid (DHA).

Among the significant components of cell membranes are the phospholipids, which contain fatty acids. The types of fatty acids in the diet determine the types of fatty acids that are available to the composition of cell membranes. A phospholipid made from a saturated fat has a different structure and is less fluid than the one that incorporates an essential fatty acid. In addition, linoleic and alpha-linolenic acids per se have an effect on the neuronal membrane fluidity index. They are able to decrease the cholesterol level in the neuronal membrane, which would otherwise decrease membrane fluidity, which in turn would make it difficult for the cell to carry out its normal functions and increase the cell's susceptibility to injury and death. These consequences for cell function are not restricted to absolute levels of FAs alone, rather it appears that the relative amounts of omega-3 fatty acids and omega- 6 fatty acids in the cell membranes are responsible for affecting cellular function.

At least six categories of PUFA effects on brain functions have been noted and discussed elsewhere [128], namely: (a) modifications of membrane fluidity; (b) modifications of the activity of membrane bound enzymes; (c) modifications of the number and affinity of receptors; (d) modifications of the function of ion channels; (e) modifications of the production and activity of neurotransmitters; and (f) signal transduction, which controls the activity of neurotransmitters and neuronal growth factors.

Included among the symptoms of essential fatty acid deficiency are fatigue, dermatological problems, immune problems, weakness, gastrointestinal disorders, heart and circulatory problems, growth retardation, and sterility. In addition to these symptom conditions, a lack of dietary essential fatty acids has been implicated in the development or aggravation of breast cancer, prostate cancer, rheumatoid arthritis, asthma, preeclampsia, depression, schizophrenia and attention deficit and hyperactivity disorders (ADHD) [128]. This list is neither exhaustive nor conclusive. 


\section{Prostaglandins}

Essential fatty acids are a special class of unsaturated fatty acids, that also act as precursors of yet another types of fatty acids. Most of the prostaglandins are derivatives of AA (itself derived from n-6) and all of them have a high physiological, hormone-like, activity level. They are involved in numerous brain functions, such as regional blood flow and permeability of various biological membranes. It has been suggested that prostaglandins are also involved in the functional level of the activity of cAMP (a second messenger) in the cells [56]. The behavioral and physiological effects of a specific ratio of $n-3 / n-6$ compound (in a ratio of 1:4) correlates with changes in the fatty acid profile and with changes in the cholesterol level [129]. It may well be that such a compound has an effect on the prostaglandin system as well and mediates the behavioral and biochemical changes that have been observed in the rat. There is evidence that prostaglandin D2 has a profound effect on sleep [37,38,43,95]. Prostaglandins enhance corticotropin-releasing factor (CRF) activity $[10,67,116,121]$, and CRF induces release of prostaglandins [97]. Prostaglandins enhance thyrotropin-releasing hormone (TRH) release and stimulate the dopaminergic and noradrenergic receptor activity $[88,123]$, while beta-endorphin inhibits prostaglandin synthesis [43].

\section{Cholesterol and fatty acids}

Cholesterol is a complex lipid that is involved with many functions of the membrane. It is well established that cholesterol decreases the membrane fluidity index, with consequences on the activity of ion channels and receptor functions and is involved in dopamine release. Moreover, cholesterol is a key molecule in the end product of the CRF-ACTH (adreno-cortico-tropic hormone) axis. Considering that steroids are derivatives of cholesterol it is of interest to find that various fatty acids have differential effects on cholesterol metabolism. Huang et al. [51] cite many studies that reliably confirm that the administration of n- 6 fatty acids reduces the level of cholesterol in the blood serum. However, n-6 fatty acids and n-3 fatty acids differ in their mode of action in cholesterol reduction, such that n- 6 fatty acids redistribute cholesterol while the n-3 fatty acids actually reduce the levels of cholesterol in the neuronal membrane [50]. This may explain why an increase in cholesterol level in the blood is found in humans who consume n-3 fatty acids supplements. It has been demonstrated that $n-3$ essential fatty acids are more effective in reducing cholesterol levels in macrophages than n-6 essential fatty acids, most probably by the differential effect on the enzyme acyl-coenzyme A activity. However, Horrocks and Harder [50] indicated that cholesterol-esterifying enzymes that incorporate free fatty acids into cholesterol esters without the participation of $\mathrm{CoA}$, are also present in the rat brain.
The mechanism by which n-3 fatty acids are able to reduce the cholesterol level is still unclear, although several hypotheses have been proposed. For example, Bourre [14] claimed that alpha-linolenic acid controls the composition of nerve membranes, which implies an inverse relationship between alpha-linolenic acid and cholesterol level. Salem and Niebylski [106] proposed that DHA or (22:6, n-3) controls the level of cholesterol as well as the composition and function of the neuronal membrane. We recently reviewed a number of studies that provided support for reducing neuronal membrane cholesterol by dietary supplementation of an $n-3 / n-6$ compound in a ratio of $1: 4$ [125]. It is possible that such a ratio optimizes uptake of PUFA into the brain and promotes fatty acid incorporation into the neuronal membranes.

\section{Specific fatty acid and the ratio between various fatty acids}

Various fatty acids serve different roles in the nervous system and in the body and it has been suggested that the nervous system has an absolute molecular species requirement for proper function [106]. Studies in our laboratory offer a confirmation for this suggestion and provide an added qualifying requirement, viz. the need for a proper ratio between the essential fatty acids. We experimentally tested our hypothesis that the ratio of n-3 and n- 6 may be a key factor in modulating behavioral and neuropharmacological effects of PUFA, and we then attempted to identify the optimal ratio [125]. To avoid the variations that occur in the composition of fatty acids in commercially prepared oils, and to exclude the possible confounding effects of other fatty acid or lipid admixtures, we used highly purified alpha-linolenic and linoleic acids. We tested a wide range of ratios of alpha-linolenic/linoleic acid (1:3, 1:3.5, 1:4, 1:4.5, 1:5, 1:5.5, 1:6 (v/v)) which were administered as dietary supplements. We found that a mixture of alpha-linolenic and linoleic acids with a ratio of 1:4 (which we referred to as SR-3) was the most effective in improving learning performance (as assessed by the Morris water maze), elevating pain threshold, improving sleep, and improving thermoregulation $[125,128]$. This compound was also able to correct learning deficits induced by the neurotoxins AF64A and 5,7-dihydroxytryptamine [127], and to provide protection from seizures induced by PTZ [126]. Also, SR-3 provides protection from bleoharospasm, which is induced by Ro4-1284 [129]. In addition, study showed that SR-3 administration exerts beneficial effects in rats given a diluted dose of the experimental allergic encephalomyelitis (EAE) toxin. The EAE rats showed learning and motor deficits as well as major changes in the fatty acids profile and the cholesterol level in frontal cortex synaptosomes. The SR-3 treatment was able to rehabilitate the changes induced by EAE to a significant degree, though not to completely reverse the deficits to the level of normal controls [129]. 
In addition, while old rats (22-24 months) showed a very poor performance in the Morris water maze, following pretreatment with SR-3 their level of performance was substantially improved.

The importance of the differentiation among the various types of fatty acids may be appreciated from noting their effects on immunological factors, viz. n-3 fatty acids suppress the synthesis of interleukin 1 (IL-1) and interleukin 6 (IL-6) and enhance the synthesis of interleukin 2 (IL-2), while $n-6$ fatty acids have the opposite effect. It should be recalled that both IL-6 and IL-1 (and to a lesser degree IL-2; [61]) promote CRF release via AA $[17,18,101]$. However, CRF inhibits the stimulating effect of IL-1 on prostaglandin synthesis [41,94].

\section{Peptide interaction with the enzyme $\mathbf{P 4 5 0}$ scc, $_{\text {, }}$ prostaglandins, cholesterol, and fatty acids}

In light of the studies reviewed above, it seems that the various fatty acids and lipids play a major role in the syntheses, release, and function of several peptides, mainly the peptides that are concerned with releasing factors. As an example, in the analysis of the CRF-ACTH-steroids axis, $\mathrm{P} 450[73,135]$ and cholesterol metabolism have been shown to exert profound effects on dopamine at the beginning of the axis, and on steroids at the end of the axis. Prostaglandins are derivatives of fatty acids, but their metabolism is modulated by P450. Prostaglandins are involved in the metabolism and functions of all neurotransmitters (including dopamine), $\mathrm{CRF}$, and steroids. The interaction between prostaglandins and ACTH is not yet clear. Cholesterol is a major molecule in the membrane, and an elevated level of cholesterol results in a decrease in the membrane fluidity and in a disturbance of the membrane function. In addition, steroids are derivatives of cholesterol. Many studies have demonstrated the role of specific fatty acids (mainly essential fatty acids of n-3 and n- 6 groups) on all aspects of synthesis, release, and receptor functions of dopamine, $\mathrm{CRF}, \mathrm{ACTH}$, and steroids.

\section{EFA ratio and stress}

We have examined the effects of a mixture of fatty acids on cortisol and cholesterol level under laboratory conditions of stress [129]. A compound of free nonesterified unsaturated fatty acids alpha-linolenic and linolenic acids in a ratio 1:4 was administered for 3 weeks prior to the injection of cortisone $(10 \mathrm{mg} / \mathrm{kg})$ or prior to immersion of rats in a $10^{\circ} \mathrm{C}$ saline bath. The results confirmed the expected elevation of cortisol and cholesterol level in stress, but more importantly the treatment prevented an elevation of blood levels of cortisol and cholesterol that were found in untreated control animals. Similarly, Morris water maze learning performance among the pretreated animals did not reflect deficits that usually accompany such stressful conditions and that can be observed in the absence of the SR-3 pretreatment.

\section{PUFA and the immune system}

Repeated demonstrations that PUFA can modify the production and activity of various components of the immune system have left unexplained the mode of action by which it exerts its effects. Several mechanisms had been proposed, including membrane fluidity (changes that might effect the capability of cytokines to bind to their respective receptors on the cell membrane); lipid peroxidation (decrease in free radical-induced tissue damage); prostaglandin production (an indirect mechanism whereby prostaglandins, which are derivatives of PUFA, modify cytokine activity); and regulation of gene expression (PUFA influences on the signal transduction pathways and modified mRNA activity). The role of PUFA in immune function is complicated by the fact that $n-3$ and n-6 have differential effects on various immune components. In a recent review, Singer and Richterheinrich [108] indicated that $n-3$ fatty acids induce a decrease in lymphocyte proliferation in humans and rats, a decrease in IL-1 production, and a decrease in IL-2 production in both humans and animals. In addition, n-3 FA decreases $\mathrm{TNF}_{\text {alpha }}$ production in humans but increases it in mice macrophages, and also decreases natural killer (NK) cell activity. On the other hand, $n-6$ increases the production of IL-2 in mice and decreases production of $\mathrm{TNF}_{\text {alpha }}$ production and NK cell activity. Still other studies have shown that linoleic acid (n-6) decreases the activity of IL-2 [129], and increases IL-1 production and tissue response to cytokines, while n-3 generally decreases IL-1 production and activity [44]. Despite some disagreement among studies, it seems that n-3 fatty acids (alpha-linolenic acid, DHA, EPA) decrease the production and activity of the pro-inflammatory cytokines (IL-1, IL-6, $\left.\mathrm{TNF}_{\text {alpha }}\right)[13,20,52,124]$ and that $\mathrm{n}-6$ family has the opposite effect $[19,44,54]$. The ability of n-3 PUFA to reduce pro-inflammatory cytokines and prostaglandin [21] lead to the proposal for the use of fish oil to relieve pain. Fish oil, rich in n-3 PUFA, has been shown to decrease IL-6, IL-10,

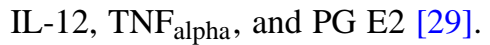

Increasingly, the salutary effects of PUFA are being examined not only with respect to their absolute level in diet, supplementation, or serum and tissue content, but also with respect to their proportional relationship to other FAs. One example of the critical nature and importance of a proper ratio can be seen in the level of anti-inflammatory IL-2 production that is increased following treatment by a mixture of $n-3$ to $n-6$ FA in a ratio of 1:3 [129], together with an increase in $n-3$ in the tissue [54].

\section{Stress}

In psychology and biology, the term "stress" is applied to describe a strain or interference that disturbs and jeopardizes 
the functioning of an organism. Organisms, both animals and humans, respond to physical and psychological stress with behavioral and physiological defenses. If the stress is too powerful, too prolonged, or is perceived as too threatening, or if the defenses are inadequate, then a somatic or comparable dysfunction may be expressed.

Outside the laboratory, stress is accepted as an unavoidable effect of living and is an especially complex phenomenon in the modern technological society. While many may profess to thrive in a stressful environment, there is little doubt that an individual's success or failure in controlling stressful situations (real or perceived) can have a profound effect on the ability to function. The ability to "cope" successfully with stress has figured prominently in anxiety and psychosomatic research. Stress has figured prominently in discussions of Health Psychology or Behavioral Medicine. Reports of a statistical link between coronary heart disease and individuals with a particular personality profile that is characterized by a behavioral pattern that manifests a life style of impatience, a sense of time urgency, hard-driving competitiveness, and a preoccupation with vocational and related deadlines ("Type A personality") has been reported numerous times. Similar correlations with other behavior profiles have suggested potential links to cancer, diabetes, and other chronic medical conditions. While different types of stress can be identified, the following discussion will refer only to psychological stress.

\section{EFA and stress}

As early as 1964, Back and Bogdanoff [8] reported elevations of free fatty acids and cholesterol among stressed people. Rosenman [102] summarized many years of research on the increased level of cholesterol among Type A behavior subjects. Subsequent studies confirmed the correlation between stressful situations and an increased level of cholesterol and free fatty acids $[4,16,24,83]$. It is not surprising, therefore, that dietary intake of soybean oil and fish oil has stress reduction properties [117]. A striking exception is the report that stressed medical students were found to exhibit lower levels of linoleic and AA (n-6), with no change in n-3 fatty acids [93,122]. Stress was shown to modify several key steps in fatty acid and lipid metabolism [75,82]. It is of interest to note that the hormones, which are released during stress (both catecholamines and glucocorticoids), serve as strong inhibitors of the first desaturase reaction, which converts linoleic and alpha-linolenic acids to longer fatty acids. Mills et al. [82] reported this finding in psychosocial stressed rats. One way to overcome the blocked biochemical step, is to administrate gamma-linoleic acid (which bypasses the blocked step in the n- 6 essential fatty acids pathway) to stressed patients in order to reduce the elevated blood pressure and the elevated catecholamine level [83]. On the other hand, administration of linoleic and alpha-linolenic acids reduce the elevated cortisol level [131].
In addition, during stress, the cardiac uptake of free FA was reduced [9]. Administration of DHA (an n-3 derivative) improved cardiac response to stress [103], decreased the level of aggression [48,107], decreased stress responses $[47,104,107,108]$, and decreased the level of prostaglandin E2 [31,103].

\section{Membrane fluidity}

The fluidity of the membrane is dependent on the lipid composition of the membrane. The protein component is very stable, but the lipid component has a high turnover rate. More specifically, the fluidity depends on (1) the transition temperature (i.e. the temperature where the membrane is converted from fluid to gel state) and (2) tight packing (where unsaturated fatty acids lower the transition temperature, and cholesterol abolishes the sharp transition temperature and disturbs packing by membrane insertion). It seems that the critical transition temperature may change during aging, along with the increase in cholesterol. The membrane fluidity index can also be regulated by the neuron in any one of a number of ways, such as: (1) desaturation of fatty acids; (2) transferring fatty acids between molecules for phospholipids with two unsaturated fatty acids (3) producing more unsaturated fatty acids, and (4) changing the tail length.

In addition to cholesterol, which decreases the membrane fluidity $[15,35,72,109]$ there are some molecules that fluidize the membrane. Prominent among them is alcohol (e.g. $[25,100,112,136])$. It is interesting to note that pretreatment with an n-6 PUFA diet prevents the alcohol effect [81]. Local anesthetics [65] and several peptides [46] can also fluidize the membrane. Finally, behaviors such as REM sleep deprivation and stress are also able to induce rigidity in the neural membrane [74].

\section{Membrane fluidity in aging-general}

Several studies indicate that the changes in the membrane fluidity index do not affect all brain regions uniformly. One study [96] identified the hippocampus, cerebellum and cortex as the most affected areas, while another study [96,114] found the cortex, hippocampus, striatum and hypothalamus as areas that are most vulnerable to change. While the reason for this selectivity is not known, two unrelated studies might be able to provide a hypothesis. One of them [7] found that the protein composition in those areas is different from the protein composition in other brain areas. The other [3] found that these areas (hippocampus and cortex) differ from other brain areas in the percentage of cholesterol.

\section{Membrane fluidity in aging-cholesterol}

Numerous studies have shown that a high level of cholesterol is correlated with a decrease in membrane fluidity and 
that the level of cholesterol is increased during aging, (e.g. $[3,5,33-36,76,85,89,90,96,111,134])$. Of particular interest are those studies that show that not only an increase in the level of cholesterol, but also in the level of the toxic metabolite, 24S-hydroxycholesterol (cerebrosterol) $[32,64]$. These studies seem to indicate that the level of cerebrosterol is even higher in patients with Alzheimer disorder [68,69,71]. The lipid lowering drugs (Lavastatine) [34,35], piracetam [86], and Ginkgo biloba [111] improve membrane fluidity by decreasing the level of cholesterol, that would otherwise inhibit the nicotine-cholinergic G-protein alpha subunit and thereby interfere with the coupling/uncoupling process [30].

It is interesting to note that one of the early studies in old rats found that complex learning per se resulted in a decrease in both cholesterol level and in membrane rigidity (hippocampus and frontal cortex) [62]. These results should be considered in the context of understanding the salutary effects of an enriched environment as a treatment option.

\section{Membrane fluidity in aging—caloric restriction}

Caloric diet restriction (reduced caloric intake with added nutritional maintenance) is one method available to improve the status of rigid membrane fluidity in the aged. Studies have shown that caloric restriction during aging increases membrane fluidity [42,55]. Mattson et al. [76] compared caloric restriction with the effect of an enriched environment, and concluded that caloric restriction is a very effective method (more effective than exercise [63]) that not only improved membrane fluidity, but also increased life span. Possible explanations to account for the effectiveness of caloric restriction include (a) the reduction of lipid peroxidation [131], (b) the decrease in the level of free radicals [131], and (c) the modification in the level of $\mathrm{Ca}^{2+}$ [39].

\section{Role of fatty acids in aging neuronal membrane}

PUFAs are major molecules responsible for regulating cellular differentiation and apoptosis [105]. Most of the studies on aging report a significant decrease in the level and turnover of PUFA $[40,98,117,130]$, especially in the hippocampus, cortex, striatum and hypothalamus. During aging, there is a significant change in the transition temperature (see above), a change which is more profound in Alzheimer patients [46]. This change causes the membrane to be more rigid. The most studied fatty acids, in this respect, are the DHA and AA. While the level of both fatty acids is very low in the neuronal membrane of aged hippocampus in rats, treatment with $\mathrm{n}-3$ fatty acids improved the membrane status $[79,80]$. Basically, there are two ways to explain the low level of PUFA in the aging brain, viz. the low rate of penetration of PUFA from the blood into the brain and an impaired biochemical machinery that would be expected to incorpo- rate and elongate the fatty acid. These two alternatives are directly related to their respective parent issues: the problem of the blood brain barrier and the dynamics of FA brain metabolism

\subsection{Blood-brain barrier}

Recently, Rapoport et al. [99] provided a detailed discussion of the complex mechanism of delivery of essential PUFA as it progresses from the blood into the brain. They also considered the effects of dietary supplements as a tool to treat states of PUFA imbalance, but they did not include aging in their review. However, structural changes in the blood-brain barrier complex, in aging and in Alzheimer patients, were reported [28,45]. Despite the knowledge about structural changes, the knowledge about functional changes is quite limited. Most of the studies did not find changes in the rate of penetration of PUFA during aging (e.g. [112,113]). Essentially, these studies showed that there is no difference between young and old rats with respect to the penetration of AA into the brain. This is in contrast to a different study that found less AA reaching the old brain [1]. It has been suggested without evidence that saturated fatty acids, but not PUFA, need a carrier to cross the blood-brain barrier, and that linoleic acid inhibits palmitic acid passage, and palmitic acid then increases linoleic passage into the brain [6]. Other studies indicated that while there is no difference in the rate of penetration of PUFA into the old brain, the difference between the young and old brain is attributed to the biochemical machinery that is different for each age group $[114,115]$.

\subsection{Fatty acid metabolism in the aging brain}

An increase in cholesterol level in the brain leads to selected functional modifications in the blood-brain barrier. Recent studies showed that various parts of the fatty acid metabolism pathways are malfunctioning in the aging brain. For example, the level of fatty acid incorporation into the membrane is inhibited and the turnover rate is very slow [115]. The activity level of the desaturase enzymes, such as delta-9 (which transfers saturated fatty acids to monounsaturated fatty acids) and other elongating enzymes, is very low [66]. In addition, the pathway to phospholipids is blocked [53]. Taken together, the combination and interaction of these various activities results in a decreased membrane fluidity index.

\section{Oxidative stress-free radicals}

Research indicates that the vulnerability to an oxidative stressor increases the deleterious effects of aging [57-59]. Oxidative stress at the cellular level results from many factors, including exposure to alcohol, medications, trauma, cold, toxins or radiation. In short, oxidative stress is a 
condition of an increase in free radicals and a decrease in antioxidants.

Recent studies have shown that the oxidative stress increases the cholesterol level in the brain [29,57,118,132,133]. In young animals oxidative stress can raise the level of brain cholesterol to the level of aged rats [29]. One possible mechanism to the harmful effects of the oxidative stress is the finding that the stress induced an increase in lipid peroxidation by ATP via $\mathrm{Ca}^{2+}[22,26,120]$. Some successful efforts to correct the effects of the stress via special food supplements have been reported [11,12,57-60,119], including PUFA supplements that can reverse the alcohol effects on the membrane [81], and increase the activity of certain membrane bound enzymes in different brain areas [110].

\section{Oxidative stress and LTP}

LTP is operationally defined as a long-lasting increase in synaptic efficacy, following high-frequency stimulation of afferent fibers. Since the first detailed description of the phenomenon in 1973, exploration of the mechanisms underlying LTP induction has been one of the most active areas of research in neuroscience. Of principal interest to those who study LTP, particularly LTP in the mammalian hippocampus, is its presumed role in the establishment of stable memories; a role consistent with "Hebbian" descriptions of memory formation. Other characteristics of LTP, including its rapid induction, persistence, and correlation with natural brain rhythms, provide circumstantial support for this connection to memory storage.

Oxidative stress, especially in older organisms, inhibits LTP (e.g. [79]) This effect of the oxidative stress is $\mathrm{Ca}^{2+}$ dependent $[87,88,91,92,133,134]$; a finding consistent with the fact that calcium inhibits synaptic plasticity. It is noteworthy that treatment with $\mathrm{n}-3$ fatty acids can restore the LTP in aged rats [70,71,77-79]. Although a detailed account of the role of sodium, potassium, and calcium in the brain is beyond the scope of this review [2,49], it is worth noting that PUFA has also been shown to modulate sodium and calcium currents in the CA1 hippocampus neurons.

\section{Hippocampus vulnerability and aging}

The hippocampus is a major brain area, which is involved in spatial learning and memory. Decreased volume and functions of the hippocampus have been reported in aged organisms and among Alzheimer patients. There is sufficient data to conclude that chronic elevation of the corticosteroids levels might lead to hippocampal regeneration $[27,84]$, since high levels of corticosterone and cortisol are toxic to the hippocampus, while estradiol protects it. The intact hippocampus plays a major role in overall inhibitory activity of the hypothalamus-pituitary-adrenal axis activi- ties. Accordingly, it has a protective role in stress situations. In aging, the response to stress which is mediated via CRF, ACTH, corticosterone (or cortisol) is enhanced and prolonged, compared to young animals. In addition, the level of the involved molecules returned very slowly to normal level. Even without a stressor, the level of corticosterone in aged rats is elevated. de Kloet et al. [27] found a reduced number of mineralocorticoid receptors (MRs) and glycocorticoid receptors (GRs) in aged hippocampus. He proposed that the normal feedback mechanism is disintegrated in the hippocampus of aged rats. Only MR-type receptors are involved in stress responses. A preliminary study from our laboratory showed that treatment with SR-3 can prevent structural changes in the hippocampus, decrease corticosterone level, and prevent a decrease in MR-type receptors in stressed young and old rats.

\section{Concluding remarks}

The aim of this review was to emphasize the role of essential fatty acids in the aging neuronal membrane. It is our position that the neuronal membrane is the prime site of action for most of the vital neuronal activities. In aging, two factors further debilitate the condition of the membrane, i.e. increased cholesterol level (and toxic cholesterol metabolites), together with a decreased level of PUFA, both of which render the membrane more rigid. A specific ratio of n-3/n-6 PUFA can protect the aged neuronal membrane against insults from many effects that would otherwise accompany aging.

\section{Acknowledgments}

We would like to thank the Rose K. Ginsburg Chair for Research into Alzheimer's Disease and The William Farber Center for Alzheimer Research for their support.

\section{References}

[1] Alberghina M, Lupo G, Anfuso CD, Infarinato S. Differential transport of palmitate through the blood-retina and the blood-brain barrier of the rat. Neurosci Lett 1994;171:133-6.

[2] Alshuaib WB, Hasan SM, Cherian SP, Mathew MV, Hasan MY, Fahim MA. Reduced potassium currents in old rat CA1 hippocampal neurons. J Neurosci Res 2001;63:176-84.

[3] Angelie E, Bonmartin A, Boudraa A, Gonnaud PM, Mallet JJ, Sappey-Marinier D. Regional differences and metabolic changes in normal aging of the human brain: proton MR spectroscopic imaging study. AJNR Am J Neuroradiol 2001;22:119-27.

[4] Arbogast BW, Neumann JK, Arbogast LY, Leeper SC, Kostrzema RM. Transient loss of serum protective activity following short-term stress: a possible biochemical link between stress and atherosclerosis. J Psychosom Res 1994;38:871-84.

[5] Aureli T, Di Cocco ME, Capuani G, Ricciolini R, Manetti C, Miccheli A, et al. Linoleic acid passage through the blood-brain 
barrier and a possible effect of age. Neurochem Res 1994;19:12933.

[6] Avellini L, Terracina L, Gaiti A. Linoleic acid passage through the blood-brain barrier and a possible effect of age. Neurochem Res 1994;19:129-33.

[7] Babu PP. Regional heterogeneity of plasma membrane proteins in rat brain. Biochem Mol Biol Int 1997;43:1033-9.

[8] Back KW, Bogdanoff MD. Plasma lipid response to leadership, conformity and deviation. In: Leiderman PH, Shapiro D, editors. Psychological approach to social behavior. London: Tavistock Publishers, 1964. p 24-42.

[9] Bagger JP, Botker HE, Thomassen A, Nielsen TT. Effects of ranolizine on ischemic threshold coronary sinus blood flow, and myocardial metabolism in coronary artery disease. Cardiovasc Drugs Ther 1997;11:479-84.

[10] Behan DP, Grigoriadis DE, Lovenberg T, Chalmers D, Heinrichs S, Liaw C, et al. Neurobiology of corticotropin releasing factor (CRF) receptors and CRF-binding protein: implications for the treatment of CNS disorders. Mol Psychiatry 1996;1:265-77.

[11] Bickford PC, Shukitt-Hale B, Joseph J. Effects of aging on cerebellar noradrenergic functions and motor learning: nutritional interventions. Mech Ageing Dev 1999;111:141-54.

[12] Bland JS. The use of complementary medicine for healthy aging. Altern Ther Health Med 1998;4:42-8.

[13] Blok WL, Deslypere JP, Demacker PN, van der Ven-Jongekrijg J, Hectors MP, van der Meer JW, et al. Pro- and anti-inflammatory cytokines in healthy volunteers fed various doses of fish oil for 1 year. Eur J Clin Invest 1997;27:1003-8.

[14] Bourre JM, Dumont O, Piciotti M, Clement M, Chaudiere J, Bonneil $\mathrm{M}$, et al. Essentiality of $\mathrm{w} 3$ fatty acids for brain structure and function. World Rev Nutr 1991;66:103-17.

[15] Boesze-Battaglia K, Schimmel RJ. Cell membrane lipid composition and distribution: implications for cell function and lessons learned from photoreceptors and platelets. J Exp Biol 1997;200:2927-36.

[16] Brennan FX, Cobb CL, Silbert LE, Watkins LR, Maier SF. Peripheral beta-adrenoreceptors and stress-induced hypercholesterolemia in rats. Phys Behav 1996;60:1307-10.

[17] Cambromero JC, Rivas FJ, Borrell J, Guaza C. Role of arachidonic acid metabolism on corticotropin-releasing factor (CRF)-release induced by interleukin-1 from superfused rat hypothalami. J Neuroimmunol 1992;39:57-66.

[18] Canonico PL, Speciale C, Sortino MA, Cronin MJ, MacLeo R, Scapagnini U. Growth hormone releasing factor (GRF) increases free arachidonate levels in the pituitary; a role for lipoxygenase products. Life Sci 1986;38:267-72.

[19] Caughey GE, Mantzioris E, Gibson RA, Cleland LG, James MJ. The effect on human tumor necrosis factor alpha and interleukin-1 beta production of diets enriched in n-3 fatty acids from vegetable oil or fish oil. Am J Clin Nutr 1996;63:116-22.

[20] Chavali SR, Zhong WW, Forse RA. Dietary alpha-linolenic acid increases $\mathrm{TNF}_{\text {alpha }}$, and decreases IL-6, IL-10 in response to LPS: effects of sesamin on the delta-5 desaturation of omega- 6 and omega-3 fatty acids in mice. Prostaglandins Leukot Essent Fatty Acids 1998;58:185-91.

[21] Chavali SR, Forse RA. Decreased production of interleukin-6 and prostoglandin E2 associated with inhibition of delta-5 desaturation of omega- 6 fatty acids in mice fed safflower oil diets supplemented with sesamol. Prostaglandins Leukot Essent Fatty Acids 1999;61:347-52.

[22] Cheng Y, Chen M, James-Kracke M, Wixom P, Sun AY. Enhanced lipid peroxidation by extracellular ATP in PC12 cells. Neurochem Res 1996;21:27-33.

[23] Choi JH, Yu BP. Brain synaptosomal aging: free radicals and membrane fluidity. Free Radic Biol Med 1995;18:133-9.

[24] Clark VR, Moore CL, Adams JH. Cholesterol concentrations and cardiovascular reactivity to stress in African American college volunteers. J Behav Med 1998;21:505-15.
[25] Colles S, Wood WG, Myers-Payne SC, Igbavboa U, Avdulov NA, Joseph J, et al. Structure and polarity of mouse brain synaptic plasma membrane: effects of ethanol in vitro and in vivo. Neurosci Res 1995;22:117-22.

[26] Conti F. Effect of long-term feeding with acetyl-L-carnitine on the age-related changes in rat brain lipid composition: a study by ${ }^{31} \mathrm{P}$ NMR spectroscopy. Neurochem Res 2000;25:395-9.

[27] de Kloet ER, Vreugdenhil E, Oitzl MS, Joels M. Brain corticosteroid receptor balance in health and disease. Endocrine Rev 1998;19:269301.

[28] de la Torre JC, Mussivand T. Can disturbed brain microcirculation cause Alzheimer's disease? Neurol Res 1993;15:146-53.

[29] Denisova NA, Cantuti-Castelvetri I, Hassan WN, Paulson KE, Joseph JA. Role of membrane lipids in regulation of vulnerability to oxidative stress in PC12 cells: implication for aging. Free Radic Biol Med 2001;30:671-8.

[30] Denisova NA, Erat SA, Kelly JF, Roth GS. Differential effect of aging on cholesterol modulation of carbachol-stimulated low-K(m) GTPase in striatal synaptosomes. Exp Gerontol 1998;33: 249-65.

[31] Deutch B. Menstrual pain in Danish women correlated with low n-3 polyunsaturated fatty acid intake. Eur J Clin Nutr 1995;49:508-16.

[32] Dietschy JM, Turley SD. Cholesterol metabolism in the brain. Curr Opin Lipidol 2001;12:105-12.

[33] Eckert GP, Cairns NJ, Maras A, Gattaz WF, Muller WE. Cholesterol modulates the membrane-disordering effects of beta-amyloid peptides in the hippocampus: specific changes in Alzheimer's disease. Dement Geriatr Cogn Disord 2000;11:181-6.

[34] Eckert GP, Cairns NJ, Muller WE. Piracetam reverses hippocampal membrane alterations in Alzheimer's disease. J Neural Transm 1999;106:757-61.

[35] Eckert GP, Kirsch C, Muller WE. Differential effects of lovastatin treatment on brain cholesterol levels in normal and apoE-deficient mice. Neuroreport 2001;12:883-7.

[36] Estilaei MR, Matson GB, Payne GS, Leach MO, Fein G, Meyerhoff DJ. Effects of chronic alcohol consumption on the broad phospholipid signal in human brain: an in vivo ${ }^{31} \mathrm{P}$ MRS study. Alcohol Clin Exp Res 2001;25:89-97.

[37] Fadda P, Martellotta MC, Gessa GL, Fratta W. Dopamine and opioids interactions in sleep deprivation. Prog Neuropsychopharmacol Biol Psychiat 1993;17:269-78.

[38] Fadda P, Martellotta MC, De Montis MG, Gessa GL, Fratta W. Dopamine D1 and opioid receptor binding changes in the limbic system of sleep deprived rats. Neurochem Int 1992;20:S153-6.

[39] Farooqui AA, Horrocks LA. Lipid peroxides in the free radical pathophysiology of brain diseases. Cell Mol Neurobiol 1998;18:599-608.

[40] Favreliere S, Stadelmann-Ingrand S, Huguet F, De Javel D, Piriou A, Tallineau C, et al. Age-related changes in ethanolamine glycerophospholipid fatty acid levels in rat frontal cortex and hippocampus. Neurobiol Aging 2000;21:653-60.

[41] Fleisher-Berkovich S, Danon A. Effect of corticotropin-releasing factor on prostaglandin synthesis in endothelial cells and fibroblasts. Endocrinology 1995;136:4068-72.

[42] Gabbita SP, Butterfield DA, Hensley K, Shaw W, Carney JM. Aging and caloric restriction affect mitochondrial respiration and lipid membrane status: an electron paramagnetic resonance investigation. Free Radic Biol Med 1997;23:191-201.

[43] Gelfand RA, Wepsic HT, Parker LN, Jadus MR. Prostaglandin E2 induces up-regulation of murine macrophage beta-endorphin receptors. Immunol Lett 1995;45:143-8.

[44] Grimble RF. Dietary lipids and the inflammatory response. Proc Nutr Soc 1998;57:535-42.

[45] Ginsberg L, Xuereb JH, Gershfeld NL. Membrane instability plasmalogen content and Alzheimer's disease. J Neurochem 1998;70:2533-8. 
[46] Giorgi PL, Biraghi M, Kantar A. Effect of desmopressin on rat brain synaptosomal membranes: a pilot study. Curr Therap Res 1998;59:172-8.

[47] Hamazaki T, Sawazaki S, Nagasawa T, Nagao Y, Kanagawa Y, Yazawa K. Administration of docosahexaenoic acid influence behavior and plasma catecholamine levels at times of psychological stress. Lipids 1999;34:S33-7.

[48] Hamazaki T, Sawazaki S, Itomura M, Asaoka E, Nagao Y, Nishimura $\mathrm{N}$, et al. The effect of docosahexaenoic acid on aggression in young adults: a placebo-controlled double-blind study. J Clin Invest 1996;97:1129-33.

[49] Hanahisa Y, Yamaguchi M. Decrease in $\mathrm{Ca}^{2+}$-ATPase activity in the brain plasma membrane of rats with increasing age: involvement of brain calcium accumulation. Int J Mol Med 2001;7:407-11.

[50] Horrocks LA, Harder HW. Fatty acids and cholesterol. In: Lajtha A, editor. Handbook of neurochemistry. New York: Plenum Press, 1983. p. 1-16.

[51] Huang YS, Koba K, Horrobin DF, Sugano M. Interrelationship between dietary protein, cholesterol and $n-6$ polyunsaturated fatty acid metabolism. Prog Lipid Res 1993;32:123-37.

[52] Hughes DA, Pinder AC. N-3 polyunsaturated fatty acids modulate the expression of functionally associated molecules on human monocytes and inhibit antigen-presentation in vitro. Clin Exp Immunol 1997;110:516-23.

[53] Ilincheta de Boschero MG, Roque ME, Salvador GA, Giusto NM Alternative pathways for phospholipid synthesis in different brain areas during aging. Exp Gerontol 2000;35:653-68.

[54] James MJ, Gibson RA, Cleland LG. Dietary polyunsaturated fatty acids and inflammatory mediator production. Am J Clin Nutr 2000;71:S343-8

[55] Ji LL, Leeuwenburgh C, Leichtweis S, Gore M, Fiebig R, Hollander $\mathrm{J}$, et al. Oxidative stress and aging. Role of exercise and its influences on antioxidant systems. Ann NY Acad Sci 1998;854:102-17.

[56] Joo F. Brain microvascular cyclic nucleotides and protein phosphorylation. In: Pardridge WM, editor. Blood brain barrier, cellular and molecular biology. New York: Raven Press, 1993. p. 267-87.

[57] Joseph JA, Denisova NA, Fisher D, Shukitt-Hale B, Bickford P, Prior R, et al. Membrane and receptor modifications of oxidative stress vulnerability in aging. Nutritional considerations. Ann NY Acad Sci 1998;854:268-76.

[58] Joseph JA, Denisova NA, Fisher D, Bickford P, Cao G. Age-related neurodegeneration and oxidative stress: putative nutritional intervention. Neurol Clin 1998;16:747-55.

[59] Joseph JA, Denisova NA, Bielinski D, Fisher DR, Shukitt-Hale B. Oxidative stress protection and vulnerability in aging: putative nutritional implications for intervention. Mech Ageing Dev 2000;116:141-53.

[60] Joseph JA, Villalobos-Molinas R, Denisova NA, Erat S, Strain J. Cholesterol: a two-edged sword in brain aging. Free Radic Biol Med 1997;22:455-62.

[61] Karanath S, Lyson K, Aguila MC, McCann SM. Effects of lutenizing-hormone, releasing hormone, alpha-melanocytestimulating hormone, naloxone, dexamethasone and indomethacin on interleukin-2-induced corticotropin-releasing factor release Neuroimmunomodulation 1995;2:166-73.

[62] Kessler AR, Yehuda S. Learning-induced changes in brain membrane cholesterol and fluidity: implications for brain aging. Int J Neurosci 1985;28:73-82.

[63] Kim JD, McCarter RJ, Yu BP. Influence of age, exercise, and dietary restriction on oxidative stress in rats. Aging (Milano) 1996;8: 123-9.

[64] Kolsch H, Ludwig M, Lutjohann D, Rao ML. Neurotoxicity of 24hydroxycholesterol, an important cholesterol elimination product of the brain, may be prevented by vitamin E and estradiol-17ß. Neural Transm 2001;108:475-88.
[65] Kopeikina LT, Kamper EF, Siafaka I, Stavridis J. Modulation of synaptosomal plasma membrane-bound enzyme activity through the perturbation of plasma membrane lipid structure by bupivacaine. Anesth Analg 1997;85:1337-43.

[66] Kumar VB, Buddhiraju M, Alshaher M, Flood JF, Morley JE. Changes in membrane fatty acids and delta- 9 desaturase in senescence accelerated (SAM) mouse hippocampus with aging. Life Sci 1999;65:1657-62.

[67] Lacroix S, Rivest S. Role of cyclo-oxygenase pathways in the stimulatory influence of immune challenge on the transcription of a specific CRF receptor subtype in the rat brain. J Chem Neuroanat 1996;10:53-71.

[68] Lutjohann D, Breuer O, Ahlborg G, Nennesmo I, Siden A, Diczfalusy U, et al. Cholesterol homeostasis in human brain: evidence for an age-dependent flux of $24 S$-hydroxycholesterol from the brain into the circulation. Proc Natl Acad Sci USA 1996;93:9799-804.

[69] Lutjohann D, Papassotiropoulos A, Bjorkhem I, Locatelli S, Bagli M, Oehring RD, et al. Plasma 24S-hydroxycholesterol (cerebrosterol) is increased in Alzheimer and vascular demented patients. J Lipid Res 2000;41:195-8.

[70] Lynch C, Mobley W. Comprehensive theory of Alzheimer's disease. The effects of cholesterol on membrane receptor trafficking. Ann NY Acad Sci 2000;924:104-11.

[71] Lynch MA. Age-related impairment in long-term potentiation in hippocampus: a role for the cytokine interleukin-1 beta? Prog Neurobiol 1998;56:571-89.

[72] Maguire PA, Druse MJ. The influence of cholesterol on synaptic fluidity dopamine D1 binding and dopamine-stimulated adenylate cyclase. Brain Res Bull 1989;23:69-74.

[73] Makita K, Falck JR, Capdevila JH. Cytochrome P450, the arachidonic acid cascade, and hypertension: new vistas for an old enzyme system. FASEB J 1996;10:1456-63.

[74] Mallick BN, Thakkar M, Gangabhagirathi R. Rapid eye movement sleep deprivation decreases membrane fluidity in the rat brain Neurosci Res 1995;22:117-22.

[75] Matsmoto K, Yobimoto K, Huong NT, Abdel-Fattah M, Van Hien $\mathrm{T}$, Watanabe H. Psychological stress-induced enhancement of brain lipid peroxidation via nitric oxide systems and its modulation by anxiolytic and anxiogenic drugs in mice. Brain Res 1999;839:7484.

[76] Mattson MP, Duan W, Lee J, Guo Z. Suppression of brain aging and neurodegenerative disorders by dietary restriction and environmental enrichment: molecular mechanisms. Mech Aging Dev 2001;122:757-78.

[77] McGahon BM, Clements MP, Lynch MA. The ability of aged rats to sustain long-term potentiation is restored when the age-related decrease in membrane arachidonic acid concentration is reversed. Neuroscience 1997;81:9-16

[78] McGahon BM, Martin DS, Horrobin DF, Lynch MA. Analysis of the effect of membrane arachidonic acid concentration on modulation of glutamate release by interleukin-1: an age-related study. Exp Gerontol 1998;33:343-54.

[79] McGahon BM, Martin DS, Horrobin DF, Lynch MA. Agerelated changes in synaptic function: analysis of the effect of dietary supplementation with omega-3 fatty acids. Neuroscience 1999;94:305-14

[80] McGahon BM, Murray CA, Horrobin DF, Lynch MA. Age-related changes in oxidative mechanisms and LTP are reversed by dietary manipulation. Neurobiol Aging 1999;20:643-53.

[81] Meehan E, Beauge F, Choquart D, Leonard BE. Influence of an n-6 polyunsaturated fatty acid-enriched diet on the development of tolerance during chronic ethanol administration in rats. Alcohol Clin Exp Res 1995;1:1441-6.

[82] Mills DE, Huang YS, Narce M, Poisson JP. Psychosocial stress catecholamines, and essential fatty acid metabolism in rats. Proc Soc Exp Biol Med 1994;205:56-61. 
[83] Mills DE, Prkachin KM, Harvey KA, Ward RP. Dietary fatty acid supplementation alters stress reactivity and performance in man. $\mathbf{J}$ Hum Hypertens 1989;3:111-6.

[84] Morrow LE, McClellan JL, Klir JJ, Kluger MJ. The CNS site of glucocorticoid negative feedback during LPS- and psychological stress-induced fevers. Am J Psychol 1996;271:732-7.

[85] Muller WE, Eckert GP, Eckert A. Piracetam: novelty in a unique mode of action. Pharmacopsychiatry 1999;32:2-9.

[86] Murphy MG, Moak CM, Rao BG. Effects of membrane polyunsaturated fatty acids on opiate peptide inhibition of basal and prostaglandin E1-stimulated cyclic AMP formation in intact NIE115 neurometabolism cells. Biochem Pharmacol 1987;36::4079_ 4084.

[87] Murray CA, Clements MP, Lynch MA. Interleukin-1 induces lipid peroxidation and membrane changes in rat hippocampus: an agerelated study. Gerontology 1999;45:136-42.

[88] Murray CA, Lynch MA. Evidence that increased hippocampal expression of the cytokine interleukin-1 beta is a common trigger for age- and stress-induced impairments in long-term potentiation. J Neurosci 1998;18:2974-81.

[89] Nagy K, Floyd RA, Simon P, Nagy I. Studies on the effect of iron overload on rat cortex synaptosomal membranes. Biochem Biophys Acta 1985;820:216-22.

[90] Nagy K, Nagy V, Bertoni-Freddari C, Nagy I. Alterations of the synaptosomal membrane "microviscosity" in the brain cortex of rats during aging and centrophenoxine treatment. Arch Gerontol Geriatr 1983;2:23-39.

[91] Norris CM, Halpain S, Foster TC. Reversal of age-related alterations in synaptic plasticity by blockade of L-type $\mathrm{Ca}^{2+}$ channels. J Neurosci 1998;18:3171-9.

[92] O’Donnell E, Vereker E, Lynch MA. Age-related impairment in LTP is accompanied by enhanced activity of stress-activated protein kinases: analysis of underlying mechanisms. Eur J Neurosci 2000;12:345-52.

[93] Ohno T, Ohinata H, Ogawa K, Kuroshima A. Fatty acid profiles of phospholipids in brown adipose tissue from rats during cold acclimation and repetitive intermittent immobilization: with special reference to docosahexaenoic acid. Jpn J Physiol 1996;46:265-70.

[94] Oka T, Aou S, Hori T. Intracerebroventriculaer injection of interleukin-1 beta induces hyperalgesia in rats. Brain Res 1993;624: $61-8$.

[95] Ongini E, Bonizzoni E, Ferri N, Milani S, Trampus M. Differential effects of dopamine D-1 and D-2 receptor antagonist antipsychotics on sleep-wake patterns in the rat. J Pharm Exp Therap 1993;266:726-31.

[96] Ohyama H, Hiramatsu M, Ogawa N, Mori A. Age-related differences in synaptosomal membrane fluidity. Biochem Mol Biol Int 1995;37:133-40.

[97] Petraglia F, Benedetto C, Florio P, D’Ambrogio G, Genazzani AD, Marozio L, et al. Effect of corticotropin-releasing factor-binding protein on prostaglandin release from cultured maternal decide and on contractile activity of human myometrium in vitro. J Clin Endocrinol Metab 1995;80:3073-6.

[98] Pu L, Igbavboa U, Wood WG, Roths JB, Kier AB, Spener F, et al. Expression of fatty acid binding proteins is altered in aged mouse brain. Mol Cell Biochem 1999;198:69-78.

[99] Rapoport SI, Chang MC, Spector AA. Delivery and turnover of plasma-derived essential PUFAs in mammalian brain. J Lipid Res 2001;42:678-85

[100] Regev R, Assaraf YG, Eytan GD. Membrane fluidization by ether other anesthetics, and certain agents abolishes P-glycoprotein ATPase activity andmodulates efflux from multidrug-resistant cells. Eur J Biochem 1999;258:18-24.

[101] Rivier C. Influence of immune signals on the hypothalamic-pituitary axis of the rodent. Front Neuroendocrinol 1995;16:151-82.

[102] Rosenman RH. Do environmental effects on human emotions cause cardiovascular disorders? ACTA Physiologica Scand Suppl 1997;640:133-6.
[103] Rossetti RG, Seiler CM, DeLuca P, Laposata M, Zurier RB Oral administration of unsaturated fatty acids: effects on human peripheral blood $\mathrm{T}$ lymphocyte proliferation. $\mathrm{J}$ Leukot Biol 1997;62:438-43.

[104] Rouseau D, Moreau D, Raederstorff D, Sergiel JP, Muggli R, Grynberg A. Is a dietary n-3 fatty acid supplement able to influence the cardiac effect of the psychological stress. Mol Cell Biochem 1998; 178:353-66

[105] Rudolph IL, Kelley DS, Klasing KC, Erickson KL. Regulation of cellular differentiation and apoptosis by fatty acids and their metabolites. Nutr Res 2001;21:381-93.

[106] Salem Jr N, Niebylski CD. The nervous system has an absolute molecular species requirement for proper function. Mol Membr Biol 1995;12:131-4.

[107] Sawazaki S, Hamazaki T, Yazawa K, Kobayashi M. The effect of docosahexaenoic acid on plasma catecholamine concentrations and glucose tolerance during long-lasting psychological stress: a double blind placebo-controlled study. J Nutr Neurosci Vitaminol 1999;45:655-65.

[108] Singer P, Richterheinrich E. Stress and fatty liver-possible indications for dietary long-chain n-3 fatty acids. Med Hypotheses 1991;36:90-4

[109] Sparks DL, Kuo YM, Roher A, Martin T, Lukas RJ. Alterations of Alzheimer's disease in the cholesterol-fed rabbit, including vascular inflammation: preliminary observation. Ann NY Acad Sci 2000;903:335-44.

[110] Srinivasarao P, Narayanareddy K, Vajreswari A, Rupalatha M, Prakash PS, Rao P. Influence of dietary fat on the activities of subcellular membrane-bound enzymes from different regions of rat brain. Neurochem Int 1997;31:789-94

[111] Stoll S, Scheuer K, Pohl O, Muller WE. Ginkgo biloba extract (EGb 761) independently improves changes in passive avoidance learning and brain membrane fluidity in the aging mouse. Pharmacopsychiatry 1996;29:144-9.

[112] Strosznajder J, Chalimoniuk M, Strosznajder RP, Albanese V, Alberghina M. Arachidonate transport through the blood-retina and blood-brain barrier of the rat during aging. Neurosci Lett 1996;209:145-8.

[113] Strosznajder J, Samochocki M, Duran M. Aging diminishes serotonin-stimulated arachidonic acid uptake and cholinergic receptor-activated acid release in rat brain cortex membrane. J Neurochem 1994;62:1048-54.

[114] Terracina L, Brunetti M, Avellini L, de Medio GE, Trovarelli G, Gaiti A. Linoleic acid metabolism in brain cortex of aged rats. Ital J Biochem 1992;41:225-35.

[115] Terracina L, Brunetti M, Avellini L, de Medio GE, Trovarelli G, Gaiti A. Arachidonic and palmitic acid utilization in aged rat brain areas. Mol Cell Biochem 1992;115:35-42.

[116] Thompson ABR, Keelan M, Clandinin MT. Feeding rats a die enriched with saturated fatty acids presents the inhibitory effects of acute and chromic ethanol exposure on the in vitro uptake of hexoses and lipids. Biochem Biophys Acta 1991;1084:122-8.

[117] Ulmann L, Mimouni V, Roux S, Porsolt R, Poisson JP. Brain and hippocampus fatty acid composition in phospholipid classes of aged-relative cognitive deficit rats. Prostaglandins Leukot Essen Fatty Acids 2001;64:189-95.

[118] Urano S, Sato Y, Otonari T, Makabe S, Suzuki S, Ogata M, et al. Aging and oxidative stress in neurodegeneration. Biofactors 1998;7:103-12.

[119] Villeponteau B, Cockrell R, Feng J. Nutraceutical interventions may delay aging and the age-related diseases. Exp Gerontol 2000;35:1405-17.

[120] Vreugdenhil M, Bruehl C, Voskuyl RA, Kang JX, Leaf A, Wadman WJ. Polyunsaturated fatty acids modulate sodium and calcium currents in CA1 neurons. Proc Natl Acad Sci USA 1996;93:12559_ 63 
[121] Watanabe T, Clarck WG, Ceriani G, Lipton JM. Elevation of plasma ACTH concentration in rabbits made febrile by systemic injection of bacterial endotoxin. Brain Res 1994;652:201-6.

[122] Williams LL, Kiecolt Glaser JK, Horrocks LA, Hillhouse JT, Glaser R. Quantitative association between altered plasma esterfied omega6 fatty-acid prosportions. Prostaglandins Leukot Essent Fatty Acids 1992;47:165-70.

[123] Yamaguchi K, Hama H. Evaluation for roles of brain prostaglandins in the catecholamine-induced vasopressin secretion in conscious rats. Brain Res 1993;607:149-53.

[124] Yano M, Kishida E, Iwasaki M, Shosuke K, Masuzawa Y. Docosahexaenoic acid and vitamin $\mathrm{E}$ can reduce human monocytic U937 cell apoptosis induced by tumor necrosis factor. J Nutr 2000;130:1095-101.

[125] Yehuda S, Carasso RL. Modulation of learning, pain threshold and thermoregulation in the rat by preparations of free purified alphalinoleic and linoleic acids: determination of optimal n-3 to n-6 ratio. Proc Natl Acad Sci USA 1993;90:10345-9.

[126] Yehuda S, Carasso RL, Mostofsky DI. Essential fatty acid preparation (SR-3) raises the seizure threshold in rats. Eur J Pharmacol 1994;254:193-8.

[127] Yehuda S, Carasso RL, Mostofsky DI. Essential fatty acid preparation (SR-3) rehabilitates learning deficits induced by AF64A and 5,7-DHT. Neuroreport 1995;6:511-5.

[128] Yehuda S, Rabinovitz S, Mostofsky DI. Effects of essential fatty acids preparation, (SR-3) on brain biochemistry and on behavioral and cognitive functions. In: Yehuda S, Mostofsky DI, editors.
Handbook of essential fatty acids biology: biochemistry physiology and behavioral neurobiology. New York: Humana Press, 1997. p. 427-52.

[129] Yehuda S, Rabinovitz S, Mostofsky DI. Essential fatty acids are mediators of brain biochemistry and cognitive functions. J Neurosci Res 1999;56:565-70.

[130] Yehuda S, Rabinovitz S, Carasso RL, Mostofsky DI. Fatty acid mixture counters stress changes in cortisol, cholesterol, and impair learning. Int J Neurosci 2000;101:73-87.

[131] Youdim KA, Martin A, Joseph JA. Essential fatty acids and the brain: possible health implications. Int J Dev Neurosci 2000;18:38399.

[132] Yu BP, Suescun EA, Yang SY. Effect of age-related lipid peroxidation on membrane fluidity and phospholopase A2: modulation by dietary restriction. Mech Ageing Dev 1992;65:17-33.

[133] Zaidi A, Michaelis ML. Effects of reactive oxygen species on brain synapticplasma membrane $\mathrm{Ca}(2+)$-ATPase. Free Radic Biol Med 1999;27:810-21.

[134] Zaidi A, Gao J, Squier TC, Michaelis ML. Age-related decrease in brain synaptic membrane $\mathrm{Ca}^{2+}$-ATPase in $\mathrm{F} 344 / \mathrm{BNF} 1$ rats. Neurobiol Aging 1998;19:487-95.

[135] Zecca L, Costi P, Mecacci C, Ito S, Terreni M, Sonnino S Interaction of human substantia nigra neuromelanin with lipids and peptides. J Neurochem 2000;74:1758-65.

[136] Zheng Z, Hungund BL. Effects of acute and chronic ethanol exposure on fatty acid ethyl ester synthases in mouse cerebellar membranes. Addict Biol 1998;3:85-90. 